\title{
Research of Subject Knowledge Revealing and Specialized Documents Searching
}

\author{
Fei YU \\ Wuhan University, Wuhan, Hubei, China
}

\begin{abstract}
It is a very important aided way by teaching college students to learn some specialized knowledge systematically and guiding them to retrieve specialized documents in professional courses teaching in universities. The paper not only explores the expressions of some specialized knowledge structures based on national criterions and professional course systems after has researched national subject documents, professional course systems and standards of book classification, but also discusses the ways of building mapping relations between literal correlation and semantic correlation based on subject category and document classification. Such building ways can make college students retrieve the documents of their subjects or specialties in library's bibliographic retrieval system accurately by using familiar subject concept terms in their specialties learning. Besides that, such kinds of ways can also have some practical means to enhance college students' specialized knowledge learning.
\end{abstract}

KEYWORDS: Specialized knowledge; Subject category; Book classification; Literal correlation mapping; Semantic correlation mapping

\section{RISE OF THE ISSUES}

About specialized course teaching in universities, how to reveal specialized knowledge and guide students to go to library and read more specialized books in order to enhance their specialized knowledge level, in some way, is a very important teaching progress. But, college students, in the stage of specialties learning, are not very familiar with the specialized knowledge and professional teachers, in this time, must describe these knowledge systematically and guide them to read more specialized documents in their majors learning. However, on the one hand, books in library are classified and arranged in accordance with the standards of "Chinese library classification", on the other hand, college students do not have complete specialized knowledge system and are not familiar with the classification system, so it may leads them to have some problems when searching documents in library. How to guide these students, who are in their specialties learning, are familiar with the corresponding knowledge and get the specialized documents they want in library collections accurately and effectively is not only the main research content of this paper, but also a significant way of auxiliary teaching, furthermore, it including to analyze students personal knowledge structures, specialized knowledge structures, library classification working and computer bibliographic retrieval system to find some effective ways to guide students search the specialized documents accurately in specialties teaching in universities.

\section{ANALYZE THE SPECIALIZED KNOWLEDGE STRUCTURES OF STUDENTS WHEN THEY START TO SPECIALTIES LEARNING}

Usually, college students, who are in specialties learning are junior ones, have finished their public basic courses and professional basic courses learning. These students, who have graduated from high schools and have studied for two years in university, now, have mastered some basic subject knowledge and specialized knowledge fundamentally. In the present stage, their accumulated specialized knowledge mainly come from two aspects, one is they have studied various specialties in all universities carefully and have knew the characteristics of the subject they choose after searched the standards of national specialty classification. The other is, they have understood the specialty from their teachers' instruction and have got something about the subject knowledge from senior students' studying and researching. According 
to the above description, college students, in this stage, have not formulated a complete specialized knowledge structure, but only have some fragment concepts. So, they must get some training about specialized knowledge systematically to enhance their academic level. Only if, at the present, specialized teachers produce some charts of complete specialized knowledge structure, can be a great help for college students to understand the characteristics of their specialties completely.

\section{RESEARCH ON THE EXPRESSION OF THE SPECIALIZED KNOWLEDGE STRUCTURES}

\subsection{Express specialized knowledge structures according to national criterions and standards}

At present, there are two kinds of subject (specialty) categories used in universities of our country. One is, "subject and specialty categories of conferred Doctor and Master's degrees and graduate students' education" ("graduate categories" for short), made by the Ministry of Education, specifies its application, that is, the base of division of subjects and specialties evaluated by the Academic Degrees Committee of the State Council Discipline Appraisal Group and degree-conferring units can confer corresponding degrees based on the subjects in this category, can be used in the field of specialty evaluation and graduate students' education ${ }^{(1)}$. The other is, "administrative regulations of undergraduate's specialties setting in universities" (undergraduate categories for short), made by the Ministry of Education, specifies the rules of specialties division, names and corresponding categories, reflects the specifications and requirements of talents' education and plays a very significant role in specialty adjustment, talents' education, degrees conferring, students employment, education statistics and talents' requirement predication, can be used in the field of undergraduate's specialty construction and undergraduates' education ${ }^{(2)}$.

The two subject categories adopt superimposed layer system as category ways, use Chinese characters and Arabic numerals as subject names and codes respectively, and then, apply the length of figures when encoding codes to reflect different hierarchical relations of various subjects, as the follows:

"graduate categories":

09 Agriculture Science

0901Crop Science

090101 Crop Cultivation and Farming System

"undergraduate categories":

09 Agriculture Science

0901 Plant Production Sciences

090901 Agriculture Science

090902 Gardening
In the above table, the professional code consists of 2 bits, 4bies and 6 bits. Usually, 2bits stands for subject category, 4bits indicates subject and 6 bits can be explained as specialty. Each code takes 2 bies as a unit to expand, expresses the hierarchical relations between subject and specialized knowledge, furthermore, each category means a kind of knowledge point. For example, some students apply "Gardening", which code is "090102", as their own specialty, by checking the above standard table, it can be drew the conclusion that "Gardening" not only belongs to "0901 Plant Production Sciences", but also belongs to "09 Agriculture Science". On the contrary, subject category "09 Agriculture Science" can be divided into "0901 Plant Production Sciences", which again can be divided into "090102 Gardening". From the above, although the specialty of "Agriculture Science", on the Chinese characters sense, is the same as the class of "Agriculture Science", they have different codes and from the relations of the codes, it can be drew the conclusion that "09 Agriculture Science" covers all kinds of subjects and specialties in Agriculture, but "0901 Agriculture Science" only means the "Agriculture Science" in "Plant Production Sciences" and without any other contents of "Agriculture Science" in other subjects.

\subsection{Express specialized Knowledge Structures by use of specialized Course System}

From the above research, it can be seen that, students can be got a very normative specialized document system and knew the relations between specialties, subjects and categories by use of national specialized subject criterions. Because national criterions are normative documents, it has very clear relationships between each subject, but simple in specialized knowledge description and can not reveal all contents covered by those knowledge. For examples:

Table1. Specialized of "Art Designing" in "undergraduate categories"

\begin{tabular}{|l|}
\hline 13 Subject category: Art \\
\hline 1305 Design Science \\
\hline 130501 Art Designing \\
\hline
\end{tabular}

When students of "Art Designing" face to the table, they may draw the following questions, how many knowledge belong to this specialty should we study and master exactly? Indeed, it can hardly answer such a question according to such two specialized subject documents mad by the Ministry Education, but only to find other ways, that is to say, introduce all specialized courses to students.

Specialized courses, which can be divided into specialized basic courses, specialized core course, specialized elective courses and specialized practical 
courses, are taught in various universities. Such teaching contents not only can give college students specialized knowledge gradually, but also reflect all knowledge points in this specialty. So, the collections of specialized course can be comprehended as the collections of basic knowledge that must mastered by the specialized students. Take "Art Design" as an example, its specialized teaching may refers the following courses: "Exhibition Space Design", "3DSMAX Senior renderings", "Furnishings and model", "Hospitality Design", "Landscape Design", etc. Such courses have the characteristics of singer literal concept, strong topicality and almost the minimal units in specialized structures. So, it can let college students to know something about knowledge points in "Art Design", only if we extract some course names from Table 3 to make corresponding wordlists. According to this way, we can let college students understand the specialties they have learnt totally from the very beginning, help them to read some documents that related to such points in their spare times and to contact with other knowledge in another specialized course studying, when they are in the stage of professional courses learning by extract all names of professional courses to make corresponding documents.

Generally, it is not only an auxiliary way to teaching, but also a method for universities to enhance their specialized courses effect by extract relationships from professional norms and names from specialized courses to produce some knowledge structure tables and pass them to students.

\section{RESEARCH OF THE WAYS IN SPECIALIZED BOOKS SEARCHING EFFECTIVELY}

Books in library are effective resources to guide students to learn specialized knowledge. In specialized courses teaching, it is also a research way in aided teaching by guide students to find some specialized books in library effectively and accurately. In order to achieve the way, it may refers some corresponding knowledge in the field of library and must takes librarians as partners to understand the functions of books retrieval system and the ways of dates indexing.

\subsection{Retrieve books by use of specialized course names}

In library's bibliographic retrieval system, specialized knowledge concept words are covered by such fields as titles, topic words, key words and abstracts. It may get some accurate results, if searchers input some regular words exactly. Consequently, in order to guide college students to find specialized documents in library, we should to extract specialized course names to make some normative term lists and pass them to these students in the course of specialized knowledge teaching.

How to make the lists? First, we should analyze words characteristics of course names. Most of specialized course names, basically, except few of them with compound words, have the characteristics of singer concept and clear theme and are the minimal unit of specialized knowledge structures. In order to not only let students find some corresponding books, but also brose the relative ones, We should to analyze course names, which including analyze compound words solely and enlarge the words with strong restricts in superior concept completely. "Furnishings and model", as an example, is a compound word, which can be interpreted as "Furnishings" and "Furniture model", such is a way of compound words uniprocessing. It not only can find the books of "Furnishings", but also search the books of "Furniture model" by use of these two words as keywords respectively, in addition, it can also get the comprehensive books that contain such two words by fuzzy searching function of the retrieval system. Also for example, the professional course name of "3DSMAX Senior Rendering", which only refers to "Senior Rendering" in 3DSMAX and can get the word of "3DSMAX" by expand to its superior concept, is a word with strong finiteness. When college students retrieve bibliographic data by using "3DSMAX" can get more corresponding books. Such two examples adopt two analytic regulations to treat specialized books, one is "expand the concept", which refers to course names that have limited semantic, to adds an superior concept word to expand the contents of course names to avoid omission because of the provincial retrieval words. The other is "uniprocessing", that is to treat the course names with compound words by single decomposition to get the retrieval words with single concept. We can analyze all specialized course names and get the specialized courses wordlists by using this analytic regulation.

Using such an analytic professional wordlist from specialized course names to search documents is a retrieval way of semantic correlation. Only if the corresponding words are indexed in bibliographic retrieval system, can the specialized books are retrieved accurately and effectively by computer retrieval system with the same character strings.

\subsection{Retrieve books from mapping relations between specialized courses and book classification}

We can see some effective ways of specialized books retrieval based on the literal correlation from section 4.1. But some books have not the same words with specialized course names in their titles. 
For example, a book, the collection of European private garden design, which number is TU986.2, can be classified into the specialized course of "Landscape Design". It may be omitted in library bibliographic system by use the analytical words in Table 3. In order to resolve such a problem, it must search the mapping relations between specialized course system and book classification and build some corresponding mapping relationships between wordlists for students to use.

There are two procedures in research the mapping relations between such two systems, one is analyze the names of these two systems, the other is building mapping relations. We have analyzed the specialized course names in section 4.1. Consequently, we should analyze the names of book classification first in this section.

Book classification, which consists of names, explanations, retractable architecture, is a complete concept and superimposed layer system. In classification, each category word is not isolated and its subject concept do not decided by its category names merely, but to get the subject means through restrict it into a semantic space consist of superior concept, appositive concept, subordinate concept, corresponding concept and category's explanation. Therefore, such ways of "directly used", "uniprocessing" and "expand the concept", which are resembled in section 4.1 , can be also used in book classification treatment.

Take the subject of "Landscape Design" as an example, it can be got two specialized words of "Garden Design" and "Landscape Design" by "unipricessing". In book classification, there is only one category, which name is "Garden Design" and number is "TU986.2", has literal correlation, but "Landscape Design", conversely, can not be included any kinds of corresponding names. But, in Chinese semantic environment, sometimes, it exists some relevance, synonymous and mutual inclusion relations between "Garden Design" and "Landscape Design". So, in the working of library classification, it has classified the books of "Landscape Design" into the category of "Garden Design", that is to say, it has some semantic correlations between "Landscape Design" and "Garden Design" and they can sharing the same category number of TU986.2

Books without semantic correlation like "architecture and courtyard" and "the collection of European private garden design", can be searched through the number of "TU986.2" based on sharing processing in literal correlation. It can increase college students' recall ratio in their specialized documents retrieval by using this way. So, our working, at present, is to expand a category number in specialized wordlists as the follows:
Table 2. Examples of expanded category number

\begin{tabular}{|c|c|c|}
\hline Course name & \multicolumn{2}{|c|}{ Garden and landscape Design } \\
\hline Retrieval word & Garden Design & Landscape Design \\
\hline Category number & TU986.2 & TU986.2 \\
\hline
\end{tabular}

It must need the cooperation of professional teachers and librarians to expand book catalogue numbers in professional wordlists because of the intersection of two different specialized knowledge.

\section{CONCLUSION}

The introduction of enhance college students' specialized knowledge teaching and specialized documents retrieval in this paper is very simple because of the limited time and space. But, it may be a new exploration in specialized teaching in colleges to make specialized wordlists and reveal the knowledge in subjects or specialties by using subject names, specialized names and professional course names. In addition, to build some mapping relations between professional course names and book classification names and make all specialized words sharing the same book classification number is a kind of interoperation between two different systems. This interoperation is based on semantic correlation and literal correlation, in addition, it can let college students, who are familiar with specialty classification and do not know about book classification, get some abstract book catalogue numbers and search results with highly recall ratio by use of such numbers in bibliographical retrieval system by wordlists' indexing.

It is the final solution, if it can integrate the analytic specialized name lists, which come from the subject categories and course names, into library retrieval system and let system changes the specialized names into some retrieval literatures automatically by making the access entry of subject categories.

\section{REFERENCES}

[1] The Academic degrees committee of the state council and the State education commission. 1997. Disciplines and majors' categories of conferred Doctor and Master's degrees and graduate students' education.

[2] General office of the Ministry of Education. 2011. Administrative regulations of undergraduate's majors setting in universities.

[3] Junli Yu and Shunian Chen. 2001. Document Taxonomy. Wuhan: Wuhan University Press.

[4] Yaosheng Chen. 2002. Comparisons of classification engine, bibliographic classification and literature classification. Library 10(5): 22-27. 